\title{
Use of otolith natal elemental signatures as natural tags to evaluate connectivity among open-coast fish populations
}

\author{
Julie D. Standish*, Michael Sheehy, Robert R. Warner \\ Department of Ecology, Evolution and Marine Biology, University of California, Santa Barbara, California 93106, USA
}

\begin{abstract}
Variation of trace elemental composition in fish otoliths has been successfully used to reconstruct the environmental history of fish, including the movement of early life stages among populations and habitats. Past studies have focused primarily on estuarine-dependent species, and information has been very limited for species that spawn along open coastlines, where spawning locations are not discrete and environmental gradients are less extreme. In this study, we used defined natal otolith elemental signatures from pre-pelagic larvae of the viviparous kelp rockfish Sebastes atrovirens taken from the natal source along the open coast of California and the offshore Channel Islands to identify the dispersal patterns of recently recruited individuals from the Channel Islands. Using laser ablation inductively coupled plasma mass spectrometry (LA-ICPMS), we chemically analyzed the otolith core (the portion of the otolith corresponding to the period of time prior to larval release) of recruits and compared the elemental signatures to spatially restricted natal otolith elemental signatures in southern California. Linear discriminant function analysis (DFA) revealed that the natal elemental signature of the mainland California location was not apparent in the elemental signatures of Channel Island recruit cores, suggesting a lack of exchange among the locations for the recruitment year. Several recruits had core elemental signatures that differed from all defined natal locations, suggesting that they originated from an uncharacterized site. These data demonstrate the use of natal otolith chemical data within a limited geographic area to identify larval dispersal patterns, with particular focus on sources that do not contribute to the defined locations.
\end{abstract}

KEY WORDS: Otolith chemistry · Otolith core $\cdot$ Larvae $\cdot$ Trace element - LA-ICPMS · Dispersal · Population connectivity

Resale or republication not permitted without written consent of the publisher

\section{INTRODUCTION}

The extent to which populations are connected via larval dispersal remains one of the fundamental unresolved issues in marine ecology. Quantifying the amount of larval connectivity among marine populations is crucial for efforts to describe population dynamics (Caley et al. 1996), and is necessary for the development of effective spatial management strategies (Shanks et al. 2003). Nonetheless, the level of larval exchange among marine populations remains poorly understood. Currently, explicit information on sources of larvae is unknown for any commercially important marine fish species.
Given the small size of fish and invertebrate larvae and their potential for long distance dispersal, identifying larval dispersal pathways is very challenging. Tagging techniques are impractical due to the high rates of mortality during the early life stage, requiring large numbers of tagged individuals to ensure a sufficient sample recovery (but see Jones et al. 1999, Almany et al. 2007). Consequently, most of the information on larval dispersal has come from a variety of indirect methods, including correlations between settlement and oceanographic patterns (Wing et al. 1995, Morgan et al. 2000), the rate of range expansion following invasion of exotic species (Geller 1994), and population genetics (Kinlan \& Gaines 2003). Although these meth- 
ods have provided valuable insights into the larval dispersal process, they do not provide information on the specific origin of individuals. Alternative techniques that can explicitly determine the natal source and movement of larvae are needed.

Recently, environmental markers such as the isotopic and elemental composition in the hard parts of fishes and invertebrates have shown great promise as a means to track the history and quantify movement among populations (DiBacco \& Levin 2000, Thorrold et al. 2001, Gillanders 2002, Becker et al. 2007). In fishes, this technique generally employs the otolith, a structure situated in the inner ear and used for vertical orientation and hearing. Formed during the embryonic stage, otoliths grow by the daily accretion of calcium carbonate into a proteinaceous matrix, generating a pattern of concentric rings around the central nucleus. The central nucleus forms the core of the otolith as the fish grows. Trace elements from the environment are incorporated into the calcium carbonate matrix of the otolith. The concentrations of some elements in the otolith may reflect the physical and chemical properties of the water mass in which they were formed, although not necessarily in a simple linear manner (Bath et al. 2000, Elsdon \& Gillanders 2003). In addition, since otoliths are metabolically inert, the otolith material remains unaltered after deposition and forms a permanent record of past conditions (Campana 1999). Thus, the elemental signatures within otoliths may be used as a natural tag of past environments experienced by an individual. Analyses of otoliths have been used to determine stock structure within marine species (Campana et al. 2000, Fowler et al. 2005), to detect anadromy (Howland et al. 2001), and to distinguish among individuals with different dispersal histories (Swearer et al. 1999).

More recent work has applied methods of otolith microchemistry to track the movement of individuals among habitats or regions over different life stages. This approach depends on the development of a spatial map of otolith elemental signatures from the collection of young while still resident at their source population before migration. Post-dispersed individuals are then identified to source by matching the elemental signatures at the portion of the otolith deposited during the early life stage with the elemental spatial map constructed for the young. Most studies that have used this method have focused on species that use estuaries as juvenile habitat (Forrester \& Swearer 2002, Gillanders 2002, Brown 2006). These studies take advantage of the fact that most estuaries have very large differences in salinity, temperature and anthropogenic influences, and the young spend a considerable amount of time in the juvenile nursery before joining adult populations. Consequently, the juvenile portion of the otolith is likely to be chemically distinct among estuaries and there is a substantial amount of otolith material deposited during the juvenile stage, facilitating an extensive analysis of elemental signatures.

In contrast, most marine species spend their entire lives in the marine environment where gradients in physical and chemical properties are less extreme. They also disperse early during their larval stage, resulting in the deposition of a small amount of otolith material at the site of origin. For open coast species, it has been a challenge to sample the chemistry of otoliths of larvae at their natal site and show that the signatures in the otolith are sufficiently discrete among natal locations along the open coast. Some of these problems can be solved by investigating benthically spawning or viviparous species, where the otolith core is formed prior to the pelagic stage. For instance, recent work demonstrates that the chemical composition of otoliths of kelp rockfish Sebastes atrovirens can be successfully measured from otoliths of larvae before their pelagic phase to characterize natal elemental signatures (Warner et al. 2005). Rockfish (genus Sebastes) are primitively viviparous, internally brooding young for a period of time before release of larvae to the pelagic phase, during which time the natal portion of the otolith is formed. The natal otolith signatures from pre-pelagic larvae taken from late-term brooding females varied significantly among 3 areas along the open coast around the Santa Barbara Channel and Santa Cruz Island (Warner et al. 2005).

In the present study, we expand on the previous work of Warner et al. (2005) by applying the natal source signatures to investigate larval connectivity of Sebastes atrovirens within a focal geographic region in southern California. We assayed otolith cores of recruits sampled from Santa Cruz Island and compared their elemental signatures with those from 3 defined natal localities around the Santa Barbara Channel and Santa Cruz Island during the 2002 productionrecruitment season. Since the natal elemental signatures were characterized only within a restricted geographic area, the variation of natal elemental signatures among all potential contributing source populations is unknown. Thus, the correspondence between natal location and recruit cores cannot be used to assign recruits unequivocally to site of origin, because uncharacterized sources outside of our natal sampling area may have had a similar source signature to the defined natal locations. Instead, our efforts focused on areas of non-overlap between natal sites and recruit cores to (1) identify defined natal locations that do not appear to contribute to the recruitment on Santa Cruz Island, and (2) distinguish recruits with elemental signatures that are distinctly different from the defined natal sites, and thus with a high probability of having been supplied from outside the sampling locations. 


\section{MATERIALS AND METHODS}

Species characteristics and sample collection. Kelp rockfish Sebastes atrovirens ranges from northern California to central Baja California, Mexico, and commonly occurs in nearshore subtidal kelp communities (Love et al. 2002). Adults are relatively sedentary, with home ranges of a radius of few meters (Love et al. 2002). Females release larvae from February through June and after an approximately 2 mo pelagic stage (Gilbert 2000), larvae settle to shallow coastal waters and kelp canopies during the summer and early fall.

Warner et al. (2005) documented natal signatures of Sebastes atrovirens from mainland and island locations in 2001 and 2002. However, in 2001 no recruitment of $S$. atrovirens occurred on artificial collectors (see below) at the island and mainland locations. Therefore, it was possible to compare the natal signatures and recruit core elemental signatures for the 2002 season only. From late March to May 2002, pre-pelagic larvae were obtained from late-term brooding females collected from 3 sites in southern California (see Warner et al. 2005 for more details). Only sites with more than one brood were included in this study. Pre-pelagic larval broods were sampled from Ellwood on the mainland $(\mathrm{n}=6)$, Pelican on the northern shore of Santa Cruz Island $(\mathrm{n}=2)$ and Yellowbanks on the southern shore of Santa Cruz Island $(\mathrm{n}=5)$ (Table 1, Fig. 1). Larval broods were removed and frozen in Eppendorf microcentrifuge tubes after capture.

Newly settled recruits were collected every 2 wk from artificial collectors. Each artificial collector $(1.0 \times$ $0.35 \mathrm{~m}$ diameter) was constructed using plastic mesh $(2.5 \mathrm{~cm}$ grid and $5.0 \times 7.5 \mathrm{~cm}$ grid) and moored approximately $2 \mathrm{~m}$ below the surface near rocky subtidal reefs (see Ammann 2004 for artificial collector specifics). Recruits were collected between July and August 2002 from sites on the north and south shores of Santa Cruz Island (Table 2, Fig. 1). Artificial collectors placed at several locations on the mainland did not receive recruits. All samples were frozen immediately after capture.

Table 1. Sampling scheme for broods (natal otoliths) from adult females collected during the 2002 productionrecruitment season. Natal otolith collection site, dates, female size (standard length, SL; mean $\pm \mathrm{SD}$ ) and number of broods sampled are shown. See Fig. 1 for location of sites

\begin{tabular}{|lccc|}
\hline Site & $\begin{array}{c}\text { Collection } \\
\text { date }\end{array}$ & $\begin{array}{c}\text { Female SL } \\
(\mathrm{cm})\end{array}$ & $\begin{array}{c}\text { No. of } \\
\text { broods }\end{array}$ \\
\hline Pelican & 11 Apr & $20.6 \pm 0.99$ & 2 \\
Yellowbanks & 12 Mar -9 Apr & $22.0 \pm 1.36$ & 5 \\
Ellwood & 18 Apr -9 May & $20.3 \pm 2.40$ & 6 \\
\hline
\end{tabular}

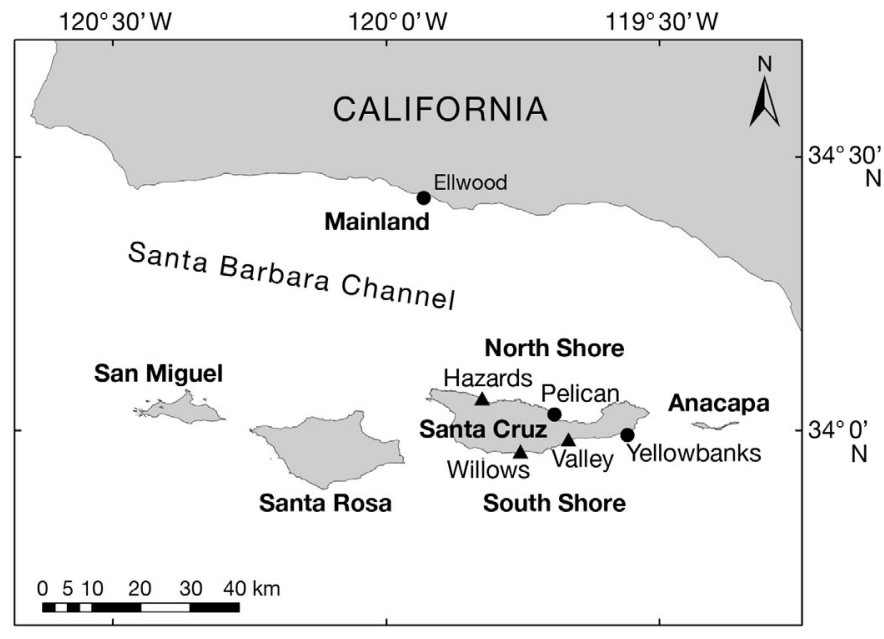

Fig. 1. Location of collection sites for pre-pelagic larvae and recruits. - sites where pre-pelagic larvae from brooding females were collected; $\boldsymbol{\Delta}$ : sites where recruits were collected

Sample preparation. Natal otolith extraction from larvae is described in detail in Warner et al. (2005). Briefly, natal otoliths were extracted by digesting larvae in semiconductor grade $15 \% \mathrm{H}_{2} \mathrm{O}_{2}$ buffered with $0.05 \mathrm{~N}$ Suprapure $\mathrm{NaOH}$. Natal otoliths were isolated from suspension by pipette, rinsed 5 times in ultra-pure water (N-pure, resistivity $>18.1 \mathrm{M} \Omega \mathrm{cm}$ ), placed onto individual clean $20 \times 20 \mathrm{~mm}$ plastic slides and air-dried in a HEPA-filter class 100 laminar flow hood. Once dry, natal otoliths from each brood were mounted onto double-sided tape $\left(\mathrm{Scotch}^{\mathrm{TM}}\right)$ and stored.

Recruits were collected from Santa Cruz Island during the 2002 recruitment season. Sagittal otoliths were removed, cleaned of adhering tissue in distilled water, air-dried and stored in individual wells in multi-well polycarbonate tissue culturing trays. Otoliths from each individual were mounted sulcal side down onto $20 \times 20 \mathrm{~mm}$ plastic slides using low-viscosity epoxy resin (Buehler Epo-Thin epoxy resin). Sagittae were polished with a lapping wheel and 3 and $9 \mu \mathrm{m} 3 \mathrm{M}^{\circledR}$ diamond polishing film to expose the growth layers and the core. Otoliths were polished to within 5 to $15 \mu \mathrm{m}$ above the visible core.

Table 2. Sampling scheme for recruit otoliths collected in 2002. Collection location, dates, birthdates and pelagic larval duration ( $\mathrm{PLD}$; mean $\pm \mathrm{SD}$ ) are shown. See Fig. 1 for location of sites

\begin{tabular}{|lcrrr|}
\hline Location & $\begin{array}{c}\text { Collection } \\
\text { date }\end{array}$ & $\begin{array}{c}\text { No. of } \\
\text { recruits }\end{array}$ & Birthdate & $\begin{array}{c}\text { PLD } \\
\text { (d) }\end{array}$ \\
\hline Hazards & 2 Jul-16 Jul & 13 & 23 Apr-24 May & $60.0 \pm 6.0$ \\
Willows & 16 Jul-1 Aug & 16 & 5 May-31 May & $60.5 \pm 8.5$ \\
Valley & 16 Jul & 11 & 6 May-23 May & $62.1 \pm 5.8$ \\
\hline
\end{tabular}


To ensure that the parturition dates of recruits overlaid the reproductive period in which the pre-pelagic larvae were collected, the ages of the recruits were determined by counting daily otolith increments. Image Pro Plus (version 4.5; Media Cybernetics 2001) and an Olympus BX50 compound microscope at 400× magnification were used to visualize and count individual otolith increments. Ralston et al. (1996) observed a dark ring at the edge of the nuclear radius in larval otoliths of shortbelly rockfish Sebastes jordani and confirmed that it was an extrusion mark. We consistently observed a distinct check mark on Sebastes atrovirens otoliths at a radius of 10.0 to $13.5 \mu \mathrm{m}$, with a mean of $11.4 \mu \mathrm{m}$. The check mark was interpreted as an extrusion mark and daily increments were counted from that mark to the otolith's edge. The birthdate of each individual was determined by back-calculating age from the date of capture. The pelagic larval duration (PLD) of each individual was determined by counting the otolith increments from the extrusion mark to the settlement mark (described in Gilbert 2000).

We prepared recruit otoliths for chemical analysis following the procedures of Ruttenberg et al. (2005). Otoliths were cleaned of surface contaminants and organic material by rinsing in N-pure water and then soaking for $1 \mathrm{~h}$ in semiconductor grade $15 \% \mathrm{H}_{2} \mathrm{O}_{2}$ buffered with Suprapur 0.05N NaOH in acid-leached plastic trays. Each otolith was rinsed with N-pure water and then soaked and sonicated 3 times in $\mathrm{N}$-pure water for $5 \mathrm{~min}$. Samples were then rinsed in a final N-pure wash and air-dried in a HEPA-filtered Class 100 laminar flow hood.

Analytical methods. All samples were analyzed using a Finnigan MAT Element sector field inductively coupled plasma mass spectrometer (ICP-MS) and a VG-UV microprobe Nd:YAG 266 nm laser ablation system (see Ruttenberg et al. 2005 and Warner et al. 2005 for more details). All elements were expressed as ratios relative to $\mathrm{Ca}$ in order to standardize for variation in material ablated. The molar ratios of analyte: $\mathrm{Ca}$ were determined from the ratio of each isotope to ${ }^{48} \mathrm{Ca}$, and an isotope ratio mass bias correction was calculated from calibration solutions with known analyte:Ca ratios (see Warner et al. 2005 for more details). Briefly, natal otoliths were sampled from a brood $(n=20)$ with a series of 8 laser pulses of $0.1 \mathrm{~mJ}$ at $3 \mathrm{~Hz}$. Counts were collected for the isotopes ${ }^{24} \mathrm{Mg},{ }^{48} \mathrm{Ca}$, ${ }^{55} \mathrm{Mn},{ }^{56} \mathrm{Fe},{ }^{66} \mathrm{Zn},{ }^{86} \mathrm{Sr},{ }^{138} \mathrm{Ba}$, and ${ }^{208} \mathrm{~Pb}$. We used the lowest resolution to produce the greatest signal intensity. $\mathrm{Ba}, \mathrm{Mg}, \mathrm{Pb}$ and $\mathrm{Sr}$ were acquired at low resolution $(R=300)$, whereas $\mathrm{Mn}, \mathrm{Fe}$ and $\mathrm{Zn}$ were acquired at medium resolution $(R=3000)$ because of molecular interferences. For each larval brood, 10 otoliths were analyzed for the medium resolution elements $(\mathrm{Mg}, \mathrm{Ca}$,
$\mathrm{Mn}, \mathrm{Fe}$, and $\mathrm{Zn}$ ) and 10 otoliths were analyzed for the low resolution elements $(\mathrm{Mg}, \mathrm{Ca}, \mathrm{Sr}, \mathrm{Ba}$ and $\mathrm{Pb})$. Due to the small size of natal otoliths ( $\sim 30 \mu \mathrm{m}$ diameter $)$, all material from a single otolith was consumed during acquisition.

Recruit otoliths were analyzed for the chemical composition of the core. We isolated the material associated with the core using a series of small, discrete vertical pits, each comprised of 8 laser pulses $(0.1 \mathrm{~mJ}$ at $3 \mathrm{~Hz}$ ) from the surface of the otolith through the visible core (for specific methods see Ruttenberg et al. 2005). This approach of discrete, successive pits approximates the amount of material analyzed when ablating natal otoliths and likely minimizes the material not associated with the core. Previous work has shown that the cores of otoliths in general contain elevated Mn (Brophy et al. 2004, Ruttenberg et al. 2005), which has been shown to be an accurate indicator of the location of the natal core of the otolith for Sebastes atrovirens recruits (Ruttenberg et al. 2005). We identified the specific pit containing the core material using elevated concentrations of Mn (at least $3 \times$ higher than surrounding material) as a proxy for the precise location of the core.

When analyzing the core of the recruit otolith, we were constrained to using only one resolution for all elements because the core of the otolith is very small and is contained within one ablation pit. Because we used a spike in Mn as an indicator of the location of the core and $\mathrm{Mn}$ is only detectable at medium resolution, all elements analyzed (Mg, Ca, Mn, Fe, Zn, Sr, Ba, Pb) for recruit cores were acquired using medium resolution. All molecular interferences at medium resolution were insignificant relative to the total mass signal $(<5 \%)$ and were therefore not a source of contamination. Because we analyzed recruit cores at medium resolution, the $\mathrm{Pb}$ signal strength was low and values were consistently below detection limits. As a result, we excluded this element from all natal-recruit comparisons. In addition, the concentrations of Fe and $\mathrm{Zn}$ were found to be very elevated in natal otoliths relative to recruit cores. Because Fe and $\mathrm{Zn}$ are susceptible to contamination by anthropogenic sources in the laboratory and the preparation techniques varied between sample types, we excluded Fe and $\mathrm{Zn}$ from further analyses.

Limits of detection for each element, calculated as $3 \times \mathrm{SD}$ of $1 \% \mathrm{HNO}_{3}$ blank sample analyzed after every otolith, and mean estimates of precision (percent relative standard deviation, \%RSD), based on replicate measurements of a solid glass standard reference material (NIST 612), are reported in Table 3 for both otolith types. The NIST precision estimates and NISTderived mean analyte:Ca ratios showed very comparable low and medium resolution values for all elements 
Table 3. Estimates of analytical precision (\% relative standard deviation, \%RSD) and detection limits (DL) for each otolith type and element. DLs are given in $\mathrm{mmol} \mathrm{mol}^{-1}$ for

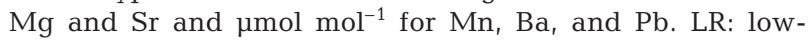
resolution mode; MR: medium-resolution mode

\begin{tabular}{|lccrr|}
\hline \multirow{2}{*}{ Element } & \multicolumn{2}{c}{ Natal otoliths } & \multicolumn{2}{c|}{\begin{tabular}{c}
\multirow{2}{*}{ Recruit otolith cores } \\
\%RSD
\end{tabular}} \\
& \%RSD & DL & DL \\
\hline $\mathrm{Mg}$ & 27.9 & $0.09(\mathrm{MR})$ & 23.6 & $0.03(\mathrm{MR})$ \\
$\mathrm{Mn}$ & 16.8 & $0.89(\mathrm{MR})$ & 6.6 & $1.16(\mathrm{MR})$ \\
$\mathrm{Sr}$ & 8.62 & $0.11(\mathrm{LR})$ & 11.2 & $0.01(\mathrm{MR})$ \\
$\mathrm{Ba}$ & 5.49 & $0.22(\mathrm{LR})$ & 10.0 & $0.71(\mathrm{MR})$ \\
$\mathrm{Pb}$ & 8.31 & $0.38(\mathrm{LR})$ & 13.3 & $11.61(\mathrm{MR})$ \\
\hline
\end{tabular}

(e.g. no significant difference between NIST low and medium resolution elemental ratios, $p>0.05$ ), indicating that the use of different resolutions for elemental concentrations (e.g. Ba and $\mathrm{Sr}$ ) in natal and recruit otoliths was reliable. Therefore, we were reasonably confident that the differences in the mean elemental concentrations between natal otoliths and recruit otoliths were not due to the analytical method.

Statistical analyses. Significant differences among locations for individual elements and multi-elemental fingerprints of natal otoliths were determined using analysis of variance (ANOVA) and multivariate analysis of variance (MANOVA). Nested ANOVAs and nested MANOVA were performed with a mixed model design with site as a fixed factor and brood(site) as a random factor. For the analyses, nested error was used as the error term to test the main effect of site. All data were $\ln$ transformed as necessary to conform to assumptions of normality.

We used discriminant function analysis (DFA) and the natal otolith chemical data from Warner et al. (2005) to visualize the spatial pattern of natal fingerprints between sites in multivariate space. The elements providing the strongest discrimination among natal locations were Ba and Sr. A jackknife re-classification procedure was used to determine the classification success of larvae from different locations (SPSS). We used a randomization test to determine whether the jackknife reclassification success rate was significantly different from random (White \& Ruttenberg 2007).

The natal otolith data were used as a reference dataset in the DFA to evaluate the assignment of recruits collected from Santa Cruz Island to natal location. Correspondence between natal chemical signatures and recruit cores in DFA space and the assignment of recruits to putative origin are not especially informative in this case, because not all source populations were characterized. However, areas of non-overlap between the natal otoliths and recruit cores in DFA space do provide meaningful information about larval exchange and connectivity. Therefore, we focused on 2 types of non-overlap: (1) defined natal location(s) indicated by the DFA assignment method that did not appear to contribute to the recruits on Santa Cruz Island; and (2) recruit cores with distinctly different elemental concentrations relative to the natal chemical signatures of the 3 defined sites - these have a high likelihood of originating from a source outside the sampled areas. To identify locations that did not contribute to 2002 recruitment, the DFA assignment method used the natal otolith data as a reference dataset to generate discriminant functions used subsequently to assign recruits of unknown membership to groups. We assumed that defined natal location(s) with very few recruits assigned to it/them indicated that the location(s) was/were not important in contributing or did not contribute at all to the recruits we collected at Santa Cruz Island for that year.

One restriction of the DFA assignment method is that it classifies recruits to only one of the sampled reference locations, even when the recruit core chemical composition is significantly different from the set of reference sources. Therefore, to identify recruit cores that were unlikely to have originated from any of the sampled natal sites, we estimated the probability that the Ba and Sr values for each recruit otolith core had been drawn from the bivariate normal distribution defined by the mean natal $\mathrm{Ba}$ and $\mathrm{Sr}$ concentrations for each site. Ba and Sr concentrations were used in this analysis because they were the 2 elements that showed the strongest discrimination among natal sites.

The brood (nested within site) variance components from the 1-way ANOVAs on Ba and $\mathrm{Sr}$ were used to estimate the variance around the mean natal concentration for each natal site. These variance estimates and the correlation between $\mathrm{Ba}$ and $\mathrm{Sr}$ in the natal data were used to define a covariance matrix for each site. Given the bivariate normal distribution defined by the natal means and covariances for each site, we estimated the cumulative probability density for each recruit otolith core. Recruits were designated as having originated from a natal source outside of our sampling area if they had probabilities more extreme than the one-tailed $\alpha$ value. We identified recruits using $\alpha=0.05,0.1,0.15$, and 0.2 .

\section{RESULTS}

\section{Natal otoliths}

The 3 natal locations showed significant amongbrood, within-site differences in trace element concentrations for every element examined (see Warner et al. 2005 for more detail, Table 4). However, despite these 
Table 4. Nested ANOVA evaluating differences in elemental concentrations in natal otoliths among broods within site and between sites for each element $\left({ }^{* * *} \mathrm{p} \leq 0.001,{ }^{*} \mathrm{p} \leq 0.05\right.$, ns $\mathrm{p}>0.05$ )

\begin{tabular}{|lcrrc|}
\hline \multirow{2}{*}{ Element } & Source & df & SS & Fratio \\
\hline \multirow{2}{*}{$\mathrm{Sr}$} & Site & 2 & 1.49 & $4.18^{*}$ \\
& Brood (Site) & 10 & 1.78 & $10.61^{* * *}$ \\
$\mathrm{Ba}$ & Error & 117 & 1.97 & \\
& Site & 2 & 8.73 & $4.08^{* *}$ \\
& Brood (Site) & 10 & 10.71 & $15.45^{* * *}$ \\
$\mathrm{Mg}$ & Error & 117 & 8.12 & \\
& Site & 2 & 0.04 & $0.05 \mathrm{~ns}$ \\
& Brood (Site) & 10 & 3.86 & $6.83^{* * *}$ \\
$\mathrm{Mn}$ & Error & 115 & 6.50 & \\
& Site & 2 & 1.08 & $0.56 \mathrm{~ns}$ \\
& Brood (Site) & 10 & 9.60 & $4.99^{* * *}$ \\
& Error & 115 & 22.12 & \\
& & & & \\
\hline
\end{tabular}

greater brood differences, there was significant variation in 2002 between locations resulting in significant site differences in $\mathrm{Ba}$ and $\mathrm{Sr}$ elemental signatures in the natal otoliths [nested MANOVA (brood nested within site), Pillai's Trace $=0.914, F_{4,20}=4.20, \mathrm{p}=$ 0.0125, Fig. 2]. DFA indicated strong spatial differenti-

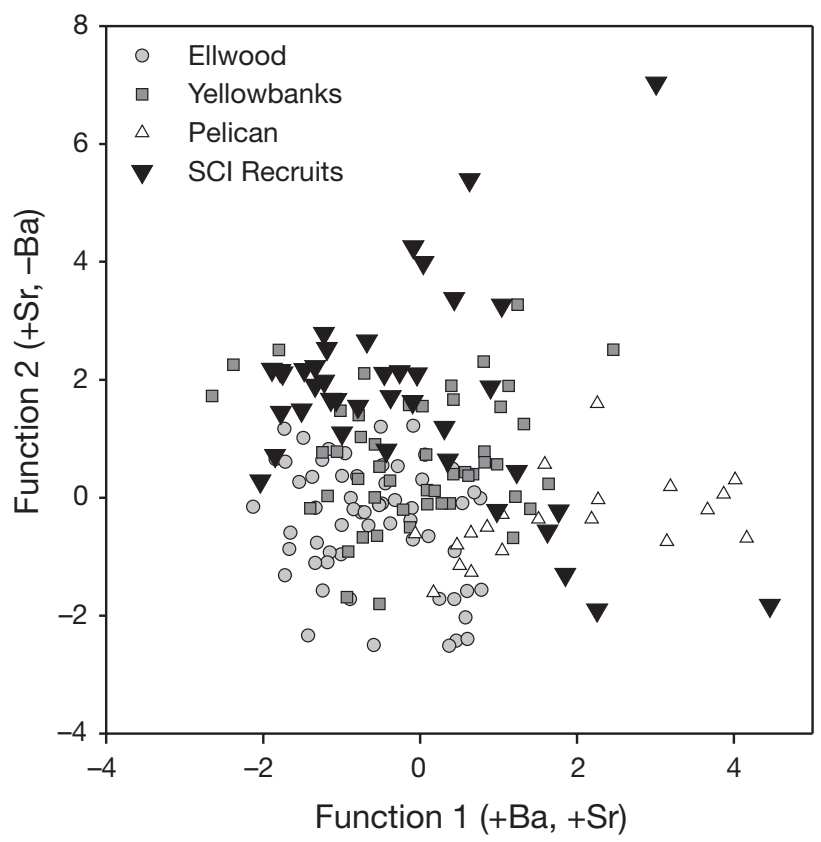

Fig. 2. Discriminant function plot of natal otoliths (by site) and of Santa Cruz Island (SCI) recruits in 2002. The discriminant functions were generated using concentrations of $\mathrm{Ba}$ and $\mathrm{Sr}$ in natal otoliths. Each point represents a single otolith. Function 1 weights are $0.662 \mathrm{Ba}$ and $0.536 \mathrm{Sr}$ and Function 2 weights are

$0.844 \mathrm{Sr}$ and $-0.750 \mathrm{Ba}$. See Fig. 1 for location of sites
Table 5. Cross-validation accuracy (\%) from linear discriminant analyses classifying natal otoliths formed in 2002 to location of formation. Columns identify site of natal otolith formation and rows identify the percent of samples classified to each site based upon canonical scores. See Fig. 1 for location of sites. Overall accuracy $=68 \%$

\begin{tabular}{|lccc|}
\hline & \multicolumn{3}{c}{ Site of formation } \\
\cline { 2 - 4 } & Pelican & Yellowbanks & Ellwood \\
\hline Pelican & 70.0 & 0.0 & 30.0 \\
Yellowbanks & 10.0 & 66.0 & 24.0 \\
Ellwood & 3.3 & 28.3 & 68.3 \\
\hline
\end{tabular}

ation between natal sites with a cross-validated (jackknife) success of $68 \%$ (Table 5). The randomization test showed that the DFA re-classification result was significantly better than chance alone $(\mathrm{p}<0.0001$, White \& Ruttenberg 2007).

\section{Recruit otoliths}

The recruits included individuals with a range of birthdates that overlaid the collection dates of prepelagic larvae (Tables $1 \& 2$ ). The average PLD for recruits was approximately 2 mo (Table 2), which is within the range previously reported for Sebastes atrovirens (Gilbert 2000).

The core of the otolith is extremely small and chemically distinct from other regions of the otolith (Brophy et al. 2004, Ruttenberg et al. 2005). Consequently, precise measurement of the core is imperative for using otolith chemistry to track larval dispersal. Since the natal otolith forms the core of the recruit otoliths, the range of elemental concentrations of recruit cores should overlap with those of natal otoliths among individuals of shared origin. Systematic differences between the elemental concentrations of natal otoliths and recruit cores could be the result of either contamination or the dilution of the effective signal from the core by the inclusion of non-core material during the ablation of the recruit core (Ruttenberg \& Warner 2006). We verified our analytical method by first comparing the elemental signatures between natal otoliths and recruit cores. We compared the general overlap of the range of values between natal otoliths and recruit cores rather than statistically comparing them since we did not have a complete representation of all possible natal elemental signatures. Thus, many of the recruits may have been produced from unsampled, chemically distinct natal sites. For $\mathrm{Ba}, \mathrm{Sr}, \mathrm{Mg}$, and $\mathrm{Mn}$, the concentrations at the core of the recruit otoliths generally overlaid the range of values measured for the natal otoliths (Fig. 3). 

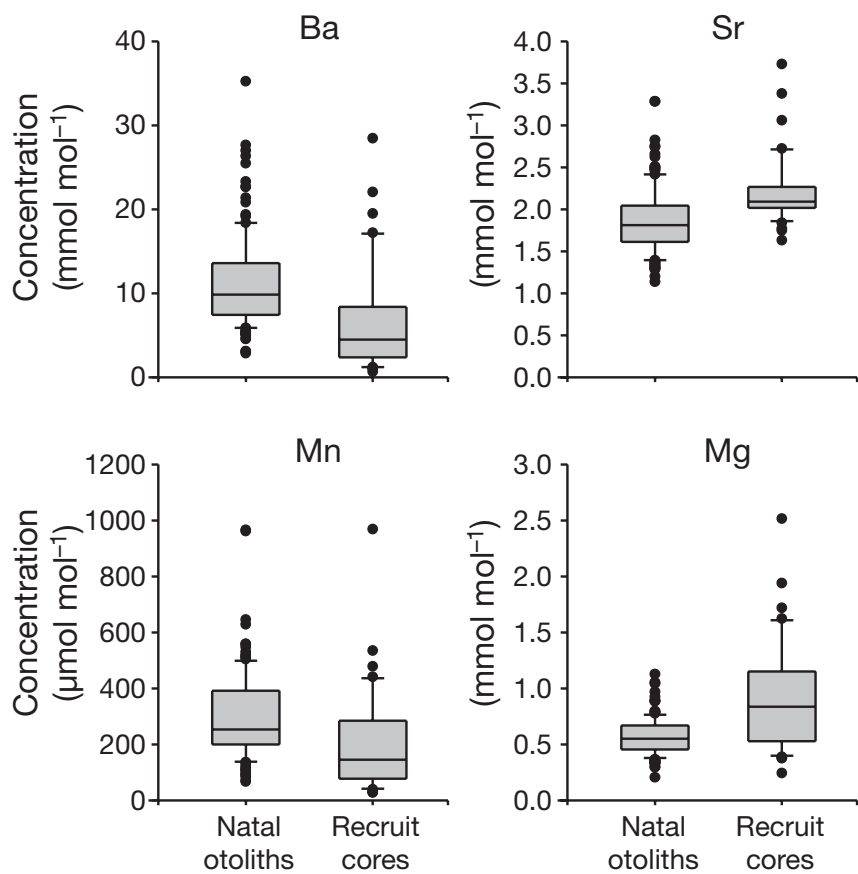

Fig. 3. Elemental concentration of $\mathrm{Ba}, \mathrm{Sr}, \mathrm{Mn}$, and $\mathrm{Mg}$ in natal otoliths and recruit otolith cores as concentrations of metal:Ca. Natal otolith elemental concentrations are from 10 pre-pelagic larvae per brood from 13 females collected from southern California (Warner et al. 2005). Recruit otolith core concentrations are from 40 recruits collected from Santa Cruz Island. The boundary of the box represents the 25th and 75th percentiles. The line within each box indicates the median. Error bars are the 10th and 90th percentiles and $\bullet$ indicate the distribution of outliers outside of these percentiles

We used the natal otolith data as a reference dataset for the DFA to classify the Santa Cruz Island recruits to location. When plotting the recruit cores within the natal DFA ordination space, we were most interested in non-overlap between the defined natal locations and recruit core signatures. Differences in elemental concentrations in recruit cores for most individuals were on the order of those seen among individuals from different broods within the same natal location, and thus some of the observed variation could be due to different brood signatures within a common source location. Despite this variation, there were substantial areas of non-overlap in elemental concentrations between the recruits and some natal locations as well as some values that were not seen in any of our natal otoliths. Using the DFA assignment method, only one island recruit in this recruitment year was assigned to the natal group from the mainland site (Table 6a). In addition, 10 of the recruit cores had Ba and $\mathrm{Sr}$ levels strikingly different from the elemental signatures of all 3 of the natal locations and were identified with a $>80 \%$ probability as having originated from outside the sampling area (Table 6b). Moreover,
Table 6. Recruit otolith cores. (a) Discriminant function analysis (DFA) assignment of recruit otolith core elemental signatures from Santa Cruz Island to natal location based on the 2002 natal classification algorithm. (b) Number of recruit cores whose cumulative probabilities were equal to or less than the indicated $\alpha$ value for all natal sites. Total number of recruit cores analyzed $=40$

\begin{tabular}{|lcc|}
\hline \multirow{2}{*}{ (a) DFA } & \multicolumn{2}{c}{ Recruit collection location } \\
Natal location & North shore & South shore \\
\hline Pelican (North Shore) & 5 & 2 \\
Yellowbanks (South Shore) & 8 & 24 \\
Ellwood (Mainland) & 0 & 1 \\
& & \\
(b) Cumulative probabilities & Recruit collection location \\
$\alpha$ & North shore & South shore \\
\hline \multirow{2}{*}{0.05} & 0 & 2 \\
0.10 & 0 & 6 \\
0.15 & 0 & 8 \\
0.20 & 1 & 9 \\
\hline
\end{tabular}

$5 \%$ of the recruits had $>95 \%$ probability of having come from outside all sampling sites (Table 6b). These distinctive core signatures were not likely the result of systematic contamination or dilution of the core signature from the inclusion of non-core material. Mn levels showed values equivalent to core signatures in other otoliths and these recruits had high levels of Sr yet low $\mathrm{Ba}$ levels relative to the mean of elemental concentrations at the 3 natal locations. Dilution of the core signature would have been signaled by low values of both elements.

\section{DISCUSSION}

In order to use otolith microchemistry to track larval dispersal, the analytical methods used must accurately sample natal material in otoliths and they must be equivalent between natal otoliths and recruit cores. We expected a general correspondence between natal otoliths and recruit cores in elemental values since the natal portion of the otolith forms the otolith core. Most of the elements present in natal otoliths were measurable in recruit cores. Recruit cores showed a wide variation of values for each element, presumably reflecting the geographic variation in elemental signatures across recruits at the site of origin. The distribution of $\mathrm{Mg}, \mathrm{Mn}, \mathrm{Ba}$ and Sr concentrations in the otolith cores of recruits overlaid the distribution of values in natal otoliths. This suggests that we accurately sampled the natal portion of the otolith and that our analytical methods were equivalent across otolith types (Fig. 3).

Earlier work by Warner et al. (2005) showed distinct geographical differences in natal otolith elemental 
concentrations from larval Sebastes atrovirens collected among several locations along the open coast in southern California in 2002. We found that Ba and Sr together produced good discrimination in natal signatures between the sites, with a reclassification (jackknife) success of $68 \%$ (Table 5, Fig. 2), suggesting that the natal signatures could be used to identify dispersal patterns within this geographic area by assaying otolith cores of recruits. We were most interested in areas of non-overlap between the natal otolith and recruit core signatures. From the DFA, there was very little overlap between the otolith core signatures of Santa Cruz Island recruits and Ellwood (mainland) natal signatures, suggesting that the mainland natal location was not an important contributor to our Santa Cruz Island samples. From the DFA assignment, only $2.5 \%$ of recruits were identified as having potentially originated from Ellwood (Table 6a), implying little connectivity between this site and the island in this recruitment year. This finding is particularly interesting since this species has the potential to disperse hundreds of $\mathrm{km}$ (Shanks et al. 2003, based on a PLD of $2 \mathrm{mo}$ ), more than sufficient for larvae to traverse the study region.

In addition, although most of the island recruits had a chemical signature similar to the natal signatures of the island sites, a portion of the recruits appeared to have originated from a source with elemental concentrations markedly different from the natal locations we sampled. Two recruits at Santa Cruz Island had a significant likelihood of coming from locations not defined by the natal sampling (Table 6b), suggesting that they did not originate from island populations. However, it remains possible that unsampled island larval sources may have had these distinctive natal otolith signatures. More comprehensive sampling of natal sources is necessary to resolve the spatial variation of natal elemental signatures around the island.

The assignment technique used here places limitations on the interpretations that can be made from the multivariate comparisons between natal otoliths and recruit cores. First, recruits cannot be unequivocally attributed to a putative source, even if the otolith core signature is similar to the defined natal locations, because not all possible source natal signatures were characterized. In our study, the majority of Santa Cruz Island recruits had core chemical signatures similar to the island natal sites, and it is certainly possible that these recruits originated from the island and were locally retained. A growing number of studies suggest that self-recruitment can occur across a wide variety of taxa and geographical localities (Jones et al. 1999, Swearer et al. 2002, Almany et al. 2007). However, given our limited data on natal signatures, we are not able to specify the level of self-recruitment to Santa
Cruz Island relative to larval input from non-local sources for this recruitment year.

A second limitation of the assignment technique is that recruits that have core multi-elemental profiles different from the defined natal locations cannot be identified to source. Elements incorporated into the otolith may be driven to some degree by the physical and chemical properties of the water mass the fish inhabits (Bath et al. 2000, Elsdon \& Gillanders 2003, Walther \& Thorrold 2006). However, accretion of elements at the core of the otolith is complex and is likely a combination of ontogenetic and environmental influences (Ruttenberg et al. 2005). For instance, Warner et al. (2005) found no correspondence between the incorporation of $\mathrm{Sr}$ and $\mathrm{Ba}$ in the natal otoliths of pre-pelagic larvae of Sebastes atrovirens and the relative concentrations in seawater at the site of origin. At this time, we still lack a complete understanding of the mechanisms controlling the incorporation of elements into the otolith core to be able to relate concentrations in otoliths to specific environmental properties of water and thereby predict the source of an individual from core chemistry alone.

Ultimately, a more complete knowledge of the geographic and temporal variation in natal elemental signatures is needed for a comprehensive study of exchange among populations and assignment of individuals to source populations. Ideally, natal signatures would vary over a spatial scale that permits sampling. Additionally, knowledge of the temporal consistency of spatial pattern would be helpful to determine the necessity for surveying natal signatures for each reproductive event. For the natal signatures of Sebastes atrovirens, Ba showed the same pattern of geographical concentration differences between 2001 and 2002, but $\mathrm{Sr}$ did not exhibit temporal consistency among locations (Warner et al. 2005).

If the spatial scale at which natal signatures vary is not compatible with a feasible sampling scheme, an alternative approach could focus solely on the spatial pattern of elemental concentrations in the otoliths of recruits. Assaying the otoliths of post-larval recruits across a broad geographic region and identifying groupings based on otolith elemental core signatures (assuming these groups represent different natal origins) may be such an approach. The spatial pattern produced from this approach can provide information about dispersal scales, i.e. the degree to which different populations receive recruits from different sources. The method is very similar to a population genetic approach and does not rely on explicit knowledge of the source of the individual. To evaluate larval dispersal, Miller \& Shanks (2004) measured the otolith chemical signatures of recruits of the black rockfish Sebastes melanops at discrete regions along the otolith 
representing the early larval to late-larval/early juvenile periods. A DFA based on the elemental signatures at each otolith region grouped an average of 67 to $81 \%$ of fish to their collection location, suggesting that fish recruiting to areas $120 \mathrm{~km}$ apart (the distance between the closest collection locations) likely had separate origins and trajectories during their early larval and pelagic juvenile period.

In summary, this study demonstrates the feasibility and potential limitations of using natal otolith chemical data to analyze larval connectivity patterns within a focal geographic region. We show that the core material of recruits is chemically comparable to natal otoliths of pre-pelagic larvae. Comparing the natal elemental signatures with the recruit cores in multivariate space, we found that the mainland site appeared to contribute very little to the recruits on Santa Cruz Island, suggesting a lack of exchange among these locations for this recruitment year. Furthermore, a portion of the recruits to Santa Cruz Island in 2002 had otolith core signatures distinctly different from the defined natal locations, suggesting that they came from a site not characterized by our natal sampling. Since recruitment patterns, dispersal trajectories, and the extent of connectivity are likely to vary from year to year, studies that include multi-year sampling are needed to determine how consistent these patterns are. Although more information about the spatial and temporal variations of natal elemental signatures is needed, our results indicate that elemental signatures in otoliths hold promise in studies of larval dispersal and exchange among locations along the open coast.

Acknowledgements. We are grateful to K. Cox, N. Kashef, and D. Stafford for help with otolith preparation. We also thank G. Paradis for assistance in the laboratory and J. White for assistance with programming and statistics. Financial support was generously provided by the Partnership for the Interdisciplinary Studies of Coastal Oceans (PISCO), funded by the David and Lucile Packard and Gordon and Betty Moore Foundations, the University of California Coastal Environmental Quality Initiative, Environmental Defense, and the Graduate Division at UCSB. We further wish to thank S. Gaines and B. Ruttenberg for invaluable discussions and suggestions, and 3 anonymous reviewers for their thoughtful comments. This is PISCO publication no. 264.

\section{LITERATURE CITED}

Almany GR, Berumen ML, Thorrold SR, Planes S, Jones GP (2007) Local replenishment of coral reef fish populations in a marine reserve. Science 316:742-744

Ammann AJ (2004) SMURFs: standard monitoring units for the recruitment of temperate reef fishes. J Exp Mar Biol Ecol 299:135-154

Bath GE, Thorrold SR, Jones CM, Campana SE, McLaren JW, Lam JWH (2000) Strontium and barium uptake in aragonitic otoliths of marine fish. Geochim Cosmochim Acta 64: 1705-1714
Becker BJ, Levin LA, Fodrie FJ, McMillan PA (2007) Complex larval connectivity patterns among marine invertebrate populations. Proc Natl Acad Sci USA 104: 3267-3272

Brophy D, Jeffries TE, Danilowicz BS (2004) Elevated manganese concentrations at the cores of clupeid otoliths: possible environmental, physiological, or structural origins. Mar Biol 144:779-786

Brown JA (2006) Using the chemical composition of otoliths to evaluate the nursery role of estuaries for English sole Pleuronectes vetulus populations. Mar Ecol Prog Ser 306: 269-281

Caley MJ, Carr MH, Hixon MA, Hughes TP, Jones GP, Menge BA (1996) Recruitment and the local dynamics of open marine populations. Annu Rev Ecol Syst 27:477-500

Campana SE (1999) Chemistry and composition of fish otoliths: pathways, mechanisms and applications. Mar Ecol Prog Ser 188:263-297

Campana SE, Chouinard GA, Hanson JM, Frechet A, Brattey $\mathrm{J}$ (2000) Otolith elemental fingerprints as biological tracers of fish stocks. Fish Res 46:343-357

DiBacco C, Levin LA (2000) Development and application of elemental fingerprinting to track the dispersal of marine invertebrate larvae. Limnol Oceanogr 45:871-880

Elsdon TS, Gillanders BM (2003) Relationship between water and otolith elemental concentrations in juvenile black bream Acanthopagrus butcheri. Mar Ecol Prog Ser 260: 263-272

Forrester GE, Swearer SE (2002) Trace elements in otoliths indicate the use of open-coast versus bay nursery habitats by juvenile California halibut. Mar Ecol Prog Ser 241: 201-213

Fowler AJ, Gillanders BM, Hall KC (2005) Relationship between elemental concentration and age from otoliths of adult snapper (Pagrus auratus, Sparidae): implications for movement and stock structure. Mar Freshw Res 56: 661-676

Geller JB (1994) Marine biological invasions as models of dispersal: tracking secondary spread and introgressive gene flow. Calif Coop Ocean Fish Invest Rep 35:68-72

Gilbert EA (2000) Molecular genetic analysis of temporal recruitment pulses in juvenile kelp rockfish. MA thesis, San Francisco State University, San Francisco, CA

Gillanders BM (2002) Connectivity between juvenile and adult fish populations: do adults remain near their recruitment estuaries? Mar Ecol Prog Ser 240:215-223

Howland KL, Tonn WM, Babaluk JA, Tallman RF (2001) Identification of freshwater and anadromous inconnu in the Mackenzie river system by analysis of otolith strontium. Trans Am Fish Soc 130:725-741

Jones GP, Milicich MJ, Emslie MJ, Lunow C (1999) Selfrecruitment in a coral reef fish population. Nature 402: 802-804

Kinlan BP, Gaines SD (2003) Propagule dispersal in marine and terrestrial environments: a community perspective. Ecology 84:2007-2020

Love MS, Yoklavich MM, Thorsteinson L (2002) The rockfishes of the northeast Pacific. University of California Press, Berkeley, CA

Miller JA, Shanks AL (2004) Evidence for limited larval dispersal in black rockfish (Sebastes melanops): implications for population structure and marine-reserve design. Can J Fish Aquat Sci 61:1723-1735

Morgan LE, Wing SR, Botsford LW, Lundquist CJ, Diehl JM (2000) Spatial variability in red sea urchin (Strongylocentrotus franciscanus) recruitment in northern California. Fish Oceanogr 9:83-98 
Ralston S, Brothers EB, Roberts DA, Sakuma KM (1996) Accuracy of age estimates for larval Sebastes jordani. Fish Bull 94:89-97

Ruttenberg BI, Warner RR (2006) Spatial variation in the chemical composition of natal otoliths from a reef fish in the Galapagos Islands. Mar Ecol Prog Ser 328:225-236

Ruttenberg BI, Hamilton SL, Hickford MJH, Paradis GL and others (2005) Elevated levels of trace elements in cores of otoliths and their potential for use as natural tags. Mar Ecol Prog Ser 297:273-281

Shanks AL, Grantham BA, Carr MH (2003) Propagule dispersal distance and the size and spacing of marine reserves. Ecol Appl (Suppl) 13:S159-S169

Swearer SE, Caselle JE, Lea DW, Warner RR (1999) Larval retention and recruitment in an island population of a coral-reef fish. Nature 402:799-802

Swearer SE, Shima JS, Hellberg ME, Thorrold SR and others

Editorial responsibility: Lisa Levin,

La Jolla, California, USA
(2002) Evidence of self-recruitment in demersal marine populations. Bull Mar Sci 70:251-271

Thorrold SR, Latkoczy C, Swart PK, Jones CM (2001) Natal homing in a marine fish metapopulation. Science 291: 297-299

Walther BD, Thorrold SR (2006) Water, not food, contributes the majority of strontium and barium deposited in the otoliths of a marine fish. Mar Ecol Prog Ser 311:125-130

Warner RR, Swearer SE, Caselle JE, Sheehy M, Paradis G (2005) Natal trace-elemental signatures in the otoliths of an open-coast fish. Limnol Oceanogr 50:1529-1542

White JW, Ruttenberg BI (2007) Discriminant function analysis in marine ecology: some oversights and their solutions. Mar Ecol Prog Ser 329:301-305

Wing SR, Botsford LW, Largier JL, Morgan LE (1995) Spatial structure of relaxation events and crab settlement in the northern California upwelling system. Mar Ecol Prog Ser 128:199-211

Submitted: February 20, 2007; Accepted: September 10, 2007 Proofs received from author(s): February 29, 2008 